\title{
Characteristics of azo-dye onto surfactant modified chromium contained leather waste
}

\author{
Dunya Edan Al- Mammar \\ Department of Chemistry, College of Science, Baghdad University, Baghdad, Iraq.
}

\begin{abstract}
A modified low-cost material, chromium contained leather waste (MO CCLW) has been used for study the adsorption behavior of anionic dye orange II dye. The modification carried out by treated the CCLW with cetyl trimethyl ammonium bromide (CTAB) as cationic surfactant. Equilibrium isotherm models applied showed Freundlich isotherm model with the best regression coefficient $R^{2}$, followed by Temkin , Dubinin Radushkevish $D-R$ isotherm and the least value was obtained with the Langmuir isotherm. The Langmuir isotherm constant $\left(K_{L}\right)$ and the freundlich constant $(n)$ indicated a high affinity of MO CCLW for orange II dye. The separation factors $R_{L}$ values lies between 0 and 1 indicated a favorable adsorption process. Physisorption was indicated by the values of the apparent energy of adsorption obtained from the Dubinin RadushKevish isotherm. The Kinetic models pseudo-first order, Pseudo-second order, Elovich and intraparticl diffusion model were used. The data were in good agreement with Pseudo-second order rate model with intra particle diffusion being the rate controlling step. The thermodynamic measurements suggest that all process are endothermic accompanied with negative $\Delta G^{\circ}$ and positive $\Delta S^{\circ}, \Delta H^{o}$.
\end{abstract}

Keywords: Adsorption isotherm, orange II, MO CCLW, Elovich kinetic .

\section{Introduction}

Environmental pollution control has been a concerned issue in many countries .One of major environmental pollution is wastewater. The polluted water comes from the domestic and from the industries. These contaminants such as heavy metal, cyanide, phenols, turbidity and color from the industries are become a great concern to the environment and public health. Decolorization of wastewater has become one of the major issues in wastewater. This is because many industries used dyes to color their products, such as textiles, rubber ,paper ,plastics ,leather ,cosmetics ,food, and mineral processing industries [1] .These dyes are invariably left in the industrial wastes. Since they have a synthetic origin and complex aromatic molecular structures, which make them inert and difficult to biodegrade when discharged into waste streams, people overlook their undesirable nature. Dye molecules have two major components, the chromophore groups ,responsible for making the color such as $-\mathrm{C}=\mathrm{C}$ - and $-\mathrm{N}=\mathrm{N}-$, and the auxochrome groups , as for example $-\mathrm{NH}_{2},-\mathrm{OH},-\mathrm{COOH}$ and $-\mathrm{SO}_{3} \mathrm{H}$, which render the solubility of the molecules and give affinity for the fibers [2]. Azo dyes are the most common and constitute, 20 to $40 \%$ of all dyes used for coloring. These dyes have hetro-cyclical structure and one or more azo rings $(-\mathrm{N}=\mathrm{N}-)$ [3] . Due to their toxicity to humans and aquatic life as well as poor degradability, the fate of the dye compounds is a subject of the considerable interest and the destruction of these pollutants has become an important issue in recent year. it is difficult to remove the dyes from effluent, because dyes are not easily degradable and are generally not removed from wastewater by conventional wastewater systems [4] Many physical and chemical processes for color removal have been applied including coagulation , flocculation, biosorption photo - decomposition and ultrafiltration, oxidizing agents and electrochemical . Adsorption process has been found to be an efficient and economic process to remove dyes, pigments and other colorants [5] .It is also has been found to be superior to other technique for wastewater treatment in terms of initial costs, simplicity of design, ease of operation and insensitivity to toxic substances, many kinds of adsorbents have been developed for various applications such as zeolite [6]. seprolite [7] Kaolin [8], activated carbon [9] , clinoptiloite [10] and raw red mud [11].

The leather waste from the tanning industry as adsorbent to other contaminants is an interesting alternative to (I) eliminate their harmful effect on the environment and (II) provide a profitable use of these materials . Orange II azo dye has been chosen as it is inexpensive and widely used for variety of materials of nylon, silk, wool, leather. Table (1) regroups the results obtained in some recent works where the adsorption of orange II on to various adsorbent has been studied [12-18]. In recent years extensive research has been going on in the field of surfactant based separation process such as a micellar chromatograph, micellar enhanced ultrafiltration [19] and surfactant modification adsorbents. Modification of adsorbents such as clays has done by using tetrabutyl ammonium chloride [20], this organo clay have been effective used for treatment of phenols [21] .A second type of modification of adsorbent has been done by treated the adsorbent with known concentration of surfactant in order to improved the adsorption ability for adsorbent .This work concentrates on the study of azo dye (orange II ) sorption on to modified CCLW. The modification occurred by treated the 
CCLW with cationic surfactant cetyl trimethyl ammonium bromide .Different isotherms model were used to fit the equilibrium isotherm .The adsorption rates were determined quantitatively and compared by the first order, second order, Elovich and intra-particle diffusion model . Thermodynamic parameters of orange II adsorption on to modified CCLW were reported.

\subsection{Materials}

\section{Experimental}

2.1.1 Adsorbate : Orange II was procured from Fluka analytical without any purification . Orange II is an anionic azo dye . The structure of dye is given in Fig.(1) . Its IUPAC name is 4-[(2-hydroxy -1-naphthy1)azo] benzene sulfonic acid, sodium salt . 1ts molecular mass 350.32 , with molecular formula $\mathrm{C}_{16} \mathrm{H}_{11} \mathrm{~N}_{2} \mathrm{NaO}_{4} \mathrm{~S}$. It is orange-colored power soluble in water .lts C.I. number is 15510 . This dye shows $\lambda$ max at $483 \mathrm{~nm}$.A stock solution of orange II dye ( $\left.1000 \mathrm{mg} \mathrm{L}^{-1}\right)$ was prepared in distilled water .

2.1.2 Adsorbent : The chromium contained leather waste (CCLW) was obtained from AI-waffe company for leathers tanning, were cut into a small pieces, washed with distilled water and dried at $120{ }^{\circ} \mathrm{C}$ for 3 hour and finally kept in desiccator .The cetyl trimethyl ammonium bromide (CTAB), cationic surfactant with molecular mass 364.46 using as modified agent was provided by Fluka .A stock solution of CTAB (1000 mg $\mathrm{L}^{-1}$ ) was prepared in distilled water. Modified CCLW (MO CCLW ) was prepared by mixing $100 \mathrm{ml}$ of $2 \mathrm{mM}$ surfactant solution with $10 \mathrm{gm}$ of CCLW. The mixture is stirring for 3 hour at room temperature, the solution was filtered . Modified CCLW dried at $120{ }^{\circ} \mathrm{C}$ for 3 hour then kept in desiccator.

\subsection{Method}

Adsorption experiments were conducted in which aliquots of dyes solution of known initial concentration ( $\left.25-125 \mathrm{mg} \mathrm{l}^{-1}\right)$ introduced into around bottom flask containing accurately weighted amount $(0.25 \mathrm{gm})$ of the adsorbent. The flasks were shaken for a prescribed length of time and at temperature range (283-323 k) to obtain equilibrium. The adsorbent was then removed by filtration. The equilibrium of dyes concentrations were determined using the uv-visible spectrometer (Shimadzu Japan) at the maximum absorption ( $\lambda \max =483 \mathrm{~nm}$ ). The amount of dye absorbed onto the modified CCLW $\mathrm{q}_{\mathrm{e}}(\mathrm{mg} / \mathrm{g})$, was calculated by amass balance relationship. $\mathrm{q}_{\mathrm{e}}=\left(\mathrm{C}_{\mathrm{o}}-\mathrm{C}_{\mathrm{e}}\right) \mathrm{V} / \mathrm{W}$

Where $C_{o}$ and $C_{e}$ are the initial and equilibrium liquid-phase concentrations of dyes respectively (mg $\left.\mathrm{L}^{-1}\right), \mathrm{V}$ the volume of the solution $(\mathrm{L})$ and $\mathrm{W}$ the weight of adsorbent used $(\mathrm{g})$. The procedures of kinetic experiments were basically identical to those of equilibrium tests.The aqueous samples were taken at present time intervals, and the concentration of dyes were similarly measured .The structural characterization of the MO-CCLW was carried out using a Shimadzu FTIR-8400 Fourier Transform Infrared Spectrometer .The experiment was done in the range between 4000 and $400 \mathrm{~cm}^{-1}$ using transmission $\mathrm{KBr}$ pellet technique $1.00 \mathrm{gm}$ of MO-CCLW is mixed with $11.00 \mathrm{gm}$ of anhydrous $\mathrm{KBr}$ to make apellet .

\subsection{FTIR characterization}

\section{Results and Discussion}

The FTIR spectra of MO CCLW Fig.(2) suggest that the protein structure of the leather is maintained after the chromium based extraction. The protein structure is evidenced by the signal at $1627.81 \mathrm{~cm}^{-1}$ due to carbonyl group $\mathrm{C}=\mathrm{O}$ and at $1542.95 \mathrm{~cm}^{-1}$ due to $\mathrm{N}-\mathrm{H}$ [22] .

\subsection{Adsorption isotherms}

The adsorption isotherm experimental data collected at different dye concentrations and various temperatures. Four adsorption models Langmuir, Freundlich, Temken and Dubinin - Radushkevish (D-R) isotherms were used to describe the equilibrium between adsorbed dye on the mixture and dye in solution $\mathrm{C}_{\mathrm{e}}$ at a constant temperature .

\subsubsection{Langmuir isotherm}

The Langmuir isotherm assumes that the surface of any adsorbent material contains a number of active sites where the adsorbate attaches itself. This attachment can either be physical or chemical. When the attachment is via van der waals interactions. It is known as physisorption where as when it is via covalent bond, it is known as chemisorption . There is also not much interaction between the adsorbed molecules and once a saturation value has been reached, no further adsorption would take place (23). The linear form of Langmuir equation can be write in the following form :

$\mathrm{C}_{\mathrm{e}} / \mathrm{q}_{\mathrm{e}}=1 / \mathrm{K}_{\mathrm{L}}+\left(\mathrm{a} / \mathrm{K}_{\mathrm{L}}\right) \mathrm{C}_{\mathrm{e}}$

Where $\mathrm{q}_{\mathrm{e}}$ is the amount of orange II adsorbed $\left(\mathrm{mg} \cdot \mathrm{g}^{-1}\right), \mathrm{C}_{\mathrm{e}}$ is the equilibrium concentration of the adsorbate $(\mathrm{mg} / \mathrm{L})$, a is the maximum adsorption capacity for monolayer coverage, $\mathrm{K}_{\mathrm{L}}$ is Langmuir constant related to 
the affinity of binding sites (L/g). Fig.(3) shows a linear plot of $\mathrm{C}_{\mathrm{e}} / \mathrm{q}_{\mathrm{e}}$ versus $\mathrm{C}_{\mathrm{e}}$ at $293 \mathrm{k}$ obtained from Langmuir isotherm data for the adsorption of orange II by modified CCLW. The values of Langmuir constants and $\mathrm{R}^{2}$ presented in Table (2). The important characteristic of the Langmuir isotherm can be expressed by means of dimensionless constant separation factor, which is calculated using the following equation

$\mathrm{R}_{\mathrm{L}}=1 / 1+\mathrm{K}_{\mathrm{L}} \mathrm{C}_{\mathrm{O}}$

Where $\mathrm{C}_{\mathrm{o}}$ is the initial dye concentration $\left(\mathrm{g} . \mathrm{L}^{-1}\right)$ and $\mathrm{K}_{\mathrm{L}}$ is the Langmuir constant. $\mathrm{R}_{\mathrm{L}}$ values indicate the type of isotherm to be irreversible $\left(R_{L}=0\right)$, favorable $\left(O<R_{L}<1\right)$, linear $\left(R_{L}=1\right)$, or unfavorable $\left(R_{L}<1\right)$ [24] . Our results show that the adsorption of orange II dye on the modified CCLW is favorable and has an $R_{L}$ value between 0 and 1 Table (3) .

\subsubsection{Freundlich isotherm}

The well known freundlich isotherm is based on the assumption that adsorption occurs on a hetrogenouse adsorption surface having unequally available sites with different energies of adsorption [25]. The freundlich equation is given as :

$\ln \mathrm{q}_{\mathrm{e}}=\ln \mathrm{K}_{\mathrm{f}}+1 / \mathrm{n} \ln \mathrm{C}_{\mathrm{e}}$

Where $\mathrm{K}_{\mathrm{f}}(\mathrm{L} / \mathrm{mg})$ and $\mathrm{n}$ are constants incorporating factor affecting the adsorption capacity and intensity of adsorption or greatness of relationship between adsorbent and adsorbate . Fig.(4) illustrates the plot obtained for the freundlich isotherm at $293 \mathrm{k}$. The values of freundlich constant and $\mathrm{R}^{2}$ are presented in Table (2) . The freundlich isotherm describes reversible adsorption and is not restricted to the formation of monolayer . It has been found that the adsorption of orange II onto modified CCLW is favorable and has $n$ value between 1 and 10 this represents a benfical adsorption process and high affinity for the modified CCLW to the dye molecular [26].

\subsubsection{Temkin isotherm}

The Temkin isotherm model was also applied to the experimental data, unlike the Langmuir and freundlich isotherm models, this isotherm takes into account the interactions between adsorbents and the dye molecular. The isotherm can be represented by the following linear form [27] .

$\mathrm{q}_{\mathrm{e}}=\mathrm{RT} / \mathrm{b}_{\mathrm{t}}\left[\ln \left(\mathrm{a}_{\mathrm{t}} \mathrm{C}_{\mathrm{e}}\right)\right]$

where $b_{t}$ is Temkin constant related to the heat of sorption $\left(\mathrm{J} \mathrm{mol}^{-1}\right)$ and $\mathrm{a}_{\mathrm{t}}$ is Temkin isotherm constant . The values of $a_{t}, b_{t}$ were estimated from the slope and intercept of the plot of $q_{e}$ against $\ln \mathrm{C}_{e}$ Fig.(5). The values of $a_{t}, b_{t}$ and $R$ are presented in Table (2). The value of $a_{t}$ lies close to 1.00 at all temperature and $b_{t}$ decreases with increase of temperature suggesting endothermic nature of the adsorption .

\subsubsection{Dubinin-Radushkevish isotherm (D-R)}

The Dubinin - Radushkevish isotherm (D-R ) model is more general than the Langmuir isotherm since it does not assume a homogenous surface or constant sorption potential .The D-R equation is :

\section{$\operatorname{Ln} \mathrm{Q}_{\mathrm{e}}=\ln \mathrm{K}_{\mathrm{D}-\mathrm{R}}-\mathrm{B}_{\mathrm{D}} \varepsilon^{2} \quad$ (6)}

Where $\varepsilon$ Polanyi potential $=\mathrm{RT} \ln \left(1+1 / \mathrm{C}_{\mathrm{e}}\right)$

$\mathrm{Q}_{\mathrm{e}}$ is the amount of dye adsorbed per unit weight of MO-CCLW (mg.g $\left.\mathrm{g}^{-1}\right), \mathrm{C}_{\mathrm{e}}$ is the equilibrium concentration $\mathrm{mg} . \mathrm{L}^{-1}$. The constant $\mathrm{K}_{\mathrm{D}-\mathrm{R}}$ is the D-R constant representing the theoretical saturation capacity $\left(\mathrm{mg} \cdot \mathrm{g}^{-1}\right)$ and $B_{D}\left(m^{2 / J^{2}}\right)$ is a constant related to the mean free energy of adsorption per mol of the adsorbate. The value of the sorption energy ( apparent energy of adsorption) E can be correlated with $\mathrm{B}$ :

$\mathrm{E}=1 /\left(-2 \mathrm{~B}_{\mathrm{D}}\right)^{0.5}$

The value of $\ln \mathrm{Q}_{\mathrm{e}}$ against $\varepsilon^{2}$ at $298 \mathrm{~K}$ is shown in Fig. (6) , the constant $\mathrm{K}_{\mathrm{D}-\mathrm{R}}$ and $\mathrm{B}_{\mathrm{D}}$ were calculated from the intercept and slope respectively. The $\mathrm{D}-\mathrm{R}$ isotherm parameters and regression parameter $\mathrm{R}^{2}$ are given in Table (2). If the value of $\mathrm{E}$ lies between $8 \& 16 \mathrm{Kg} \mathrm{mol}^{-1}$ the sorption process is a chemisorption one , while values of below $8 \mathrm{KJ} \mathrm{mol}^{-1}$ indicates a physical adsorption [28]. Values of the apparent energy of adsorption obtained, indicated physical adsorption between MO-CCLW and the dye molecular .Comparing quality of fitting the four models of isotherms in terms of correlation coefficient, $\mathrm{R}^{2}$, it can be seen that the freundlich isotherm fits the data better than the D-R isotherm that followed by the Temkin isotherm and then the least fit was obtain with the Langmuir isotherm.

\subsection{Dynamic modeling}

The Kinetics of adsorption is important from the point of view that it controls the process efficiency. To examine the rate limiting step of the adsorption process various kinetics models have been used such as pseudofirst order and pseudo-second order kinetic models, Elovich and the intraparticle diffusion one .

\subsubsection{The pseudo-first order and pseudo-second kinetics}


The lagergreens rate equation is the most widely one used for the adsorption of a solute from a liquid solution .Thus this first order equation . [29]

$\log \left(\mathrm{q}_{1}-\mathrm{q}_{\mathrm{t}}\right)=\log \mathrm{q}_{1}-\mathrm{K}_{1} / 2.303 \mathrm{t}$

Where $\mathrm{q}_{1}$ and $\mathrm{q}_{\mathrm{t}}$ are the amounts ( $\mathrm{mg} . \mathrm{g}^{-1}$ ) of solute bound at the interface at the equilibrium and after time $\mathrm{t}(\mathrm{min})$ respectively, $\mathrm{K}_{1}$ is the rat constant of pseudo first order adsorption $\left(\min ^{-1}\right)$. The pseudo - second order kinetic model is :

$\mathrm{t} / \mathrm{q}_{\mathrm{t}}=1 / \mathrm{K}_{2} \mathrm{q}_{2}^{2}+\mathrm{t} / \mathrm{q}_{\mathrm{e}}$

Where $\mathrm{K}_{2}$ is the pseudo second order rate constant $\left(\mathrm{mg}^{-1} \cdot \mathrm{g} \cdot \mathrm{min}^{-1}\right)$. The plot validating the pseudo first model [ $\log \left(\mathrm{q}_{1}-\mathrm{q}_{\mathrm{t}}\right)$ versus $\mathrm{t}$ ] and the pseudo second order model $\left(\mathrm{t} / \mathrm{q}_{\mathrm{t}}\right.$ versus $\left.\mathrm{t}\right)$ for $100 \mathrm{mg} \cdot \mathrm{L}^{-1}$ initial concentration of the orange II at $293 \mathrm{~K}$ are given in Figs.(7) and (8) respectively. The parameters of pseudo first order and pseudo second order model are listed in Table (4). The pseudo second order kinetic model fitted better than lagergreen model. The correlation constant was higher than first order model.

\subsubsection{Elovich kinetic model [30]}

The Elovich model equation is generally expressed as

$\mathrm{q}_{\mathrm{t}}=1 / \mathrm{B}(\alpha \mathrm{B})+1 / \mathrm{B} \ln \mathrm{t}$

Where $\alpha$ is the initial adsorption rate $\left(\mathrm{mg}^{-\mathrm{g}^{-1}} \cdot \mathrm{min}^{-1}\right), \mathrm{B}$ is the adsorption constant $\left(\mathrm{g} . \mathrm{mg}^{-1}\right)$ during any one experiment. The plot of $\mathrm{q}_{\mathrm{t}}$ versus $\ln \mathrm{t}$ should yield a linear relationship for the applicability of the simple Elovich Kinetic Fig. (9). The kinetics constants obtained from the Elovich equation are listed in Table (4).The regression coefficient was found to be 0.9458 .

\subsection{Intra particle diffusion}

The dye adsorption process from aqueous solution onto porous solids involves several steps (i) transport in the solution (ii) diffusion through the liquid film surrounding the solid particle, known by external diffusion or boundary layer diffusion (iii) diffusion within the liquid included in the pore, known by internal diffusion or intra particle diffusion, (iv) adsorption or desorption on the face of the interior [31]. The first step has no rate limitation effect as the experiments were performed at rapid shaking conditions. In addition Previous studies showed that the last step is a very fast process for the adsorption of organic molecules onto porous adsorbent [32]. The most commonly used technique for identifying the mechanism involved in the sorption process is by fitting the experimental data in an intra particle diffusion plot. The plot of $\mathrm{q}_{\mathrm{t}}$ versus $\mathrm{t}^{0,5}$ represent multi linearity, which characterizes the two or more steps. The rate parameter for the intra particles diffusion model is determined using the following equation [33] .
$\mathrm{q}_{\mathrm{t}}=\mathrm{k}_{\mathrm{id}} \mathrm{t}^{0,5}+\mathrm{C}$

Thus the intra particle diffusion constant $\mathrm{k}_{\mathrm{id}}\left(\mathrm{mg} / \mathrm{g} \cdot \mathrm{min}^{0,5}\right)$, and $\mathrm{C}$ values obtained from the slope and intercept of the plot of $\mathrm{q}_{\mathrm{t}}\left(\mathrm{mg} / \mathrm{g}\right.$ ) versus time ${ }^{0,5}$ (min ), Fig.(10), for initial dye concentration $100 \mathrm{mg} \cdot \mathrm{l}^{-1}$ at 293 $k$. The $k_{i d}, C$ and $R^{2}$ values are listed in Table (4). Fig.(10) showed that the plot are not liner over the whole time range, however, they exhibit a tri - linearity revealing the extence of three successive adsorption steps . The first stage being faster than the second is attributed to the external surface adsorption correlated to the boundary larger diffusion. Consequently, the second linear part attributed to the intra particle diffusion states that this latter is highly involved in the rate control of this mechanism. The third linearity attributed to the equilibrium stage . It is worth to note the fact that the second linear plots did not pass by the origin which indicates that the intra - particle diffusion is involved in the adsorption process but it is not the only rate controlling step .

\subsection{Thermodynamic Parameters}

The thermodynamic parameters of the adsorption process such as change in free energy $\left(\Delta \mathrm{G}^{0}\right)($ J.mol $\left.{ }^{-1}\right)$, enthalpy $\left(\Delta \mathrm{H}^{0}\right)\left(\mathrm{K} \mathrm{Jmol}^{-1}\right)$ and entropy $\left(\Delta \mathrm{S}^{0}\right)\left(\mathrm{J} \mathrm{mol}^{-1}\right)$ were determined using the following equations [34].

$\mathrm{K}_{\mathrm{d}}=\mathrm{C}_{\text {solid }} / \mathrm{C}_{\text {liquid }}$

$\Delta \mathrm{G}^{0}=-\mathrm{RT} \cdot \ln \mathrm{K}_{\mathrm{d}}$

$\Delta \mathrm{G}^{0}=\Delta \mathrm{H}-\mathrm{T} \Delta \mathrm{S}^{0}$

$\operatorname{Ln} \mathrm{K}_{\mathrm{d}}=\Delta \mathrm{S} \% \mathrm{R}-\Delta \mathrm{H}^{0} / \mathrm{R} .1 / \mathrm{T}$

Where $K_{d}$ is the equilibrium constant, $C_{\text {solid }}$ is solid phase concentration at equilibrium (mg L $\left.{ }^{-1}\right), T(K)$ is the temperature , $\mathrm{R}\left(8.314 \mathrm{~J} \mathrm{~mol}^{-1} \mathrm{~K}^{-1}\right)$ is the gas constant . The values of $\Delta \mathrm{S}^{0}, \Delta \mathrm{H}^{0}$ were determined from the slopes and intercepts of the vant Hoff plots $\ln \mathrm{K}_{\mathrm{d}}$ Vs. $1 / \mathrm{T} \quad$ Fig. (11) .The calculated thermodynamic parameters based on the above function were listed in Table (5). The values $\Delta \mathrm{H}^{0}$ are positive in the range from 22.92 to $45.89 \mathrm{~K} \mathrm{~J} \mathrm{~mol}^{-1}$ indicates the physisorption. As the adsorption process is pore diffusion controlled, an increase in molecular diffusion occurs at higher temperatures leading to endothermic enthalpy of 
adsorption .The low $\Delta \mathrm{H}^{0}$ value depicts dye is physisorbed onto the modified CCLW . Furthermore, negative values of Gibbs free energy $\Delta \mathrm{G}^{0}$ shows the adsorption process is highly favorable and spontaneous at all the temperatures. However, the negative value of $\Delta \mathrm{G}^{0}$ decreased with an increase in temperature, indicating that the spontaneous nature of adsorption is inversely proportional to the temperature . The positive values of $\Delta \mathrm{S}^{0}$ show the increased disorder and randomness at the solid /solution interface during the adsorption of orange II into the adsorbent, while the adsorption there are some structural changes in the dye and the adsorbent occur . The adsorbed water molecules, which are displaced by the adsorbate species, gain more translational energy than is lost by the adsorbate ions, thus allowing the prevalence of randomness in the system. The enhancement of adsorption at higher temperature may be attributed to the enlargement of pore size and /or activation of the adsorbent surface [35].

\section{Tables and Figures}

Table (1) Comparison of the maximum monolayer adsorption capacities of orange II onto various adsorbents.

\begin{tabular}{|c|c|c|}
\hline Adsorbent & $\begin{array}{c}\text { Max monolayer } \\
\text { adsorption capacities } \\
\text { mg.g }\end{array}$ & references \\
\hline $\begin{array}{c}\text { Commercial activated carbon fibers -generated from } \\
\text { pitch ACFC }\end{array}$ & $209-438(10-60) \mathrm{C}^{0}$ & 12 \\
\hline $\begin{array}{c}\text { Commercial activated carbon fibers-made with } \\
\text { polyacrylonitrile ACFT }\end{array}$ & $25-185(10-60) \mathrm{C}^{0}$ & 12 \\
\hline Sludge adsorbent & $83-270(10-60) \mathrm{C}^{0}$ & 12 \\
\hline Bottom ash & $12.50(30) \mathrm{C}^{0}$ & 13 \\
\hline Phosphoric acid modified clam shell powder & $1017.13(25) \mathrm{C}^{0}$ & 14 \\
\hline Surfactant - modified zeolite & $3.62(35) \mathrm{C}^{0}$ & 15 \\
\hline Modified bentonite ( organophifilic fluidgel ) & $11.15(25) \mathrm{C}^{0}$ & 16 \\
\hline Titania aerogel & $402.32(30) \mathrm{C}^{0}$ & 17 \\
\hline HDTMA bentonite & $52.36(25) \mathrm{C}^{0}$ & 18 \\
\hline
\end{tabular}

Table (2) Equilibrium isotherm parameters

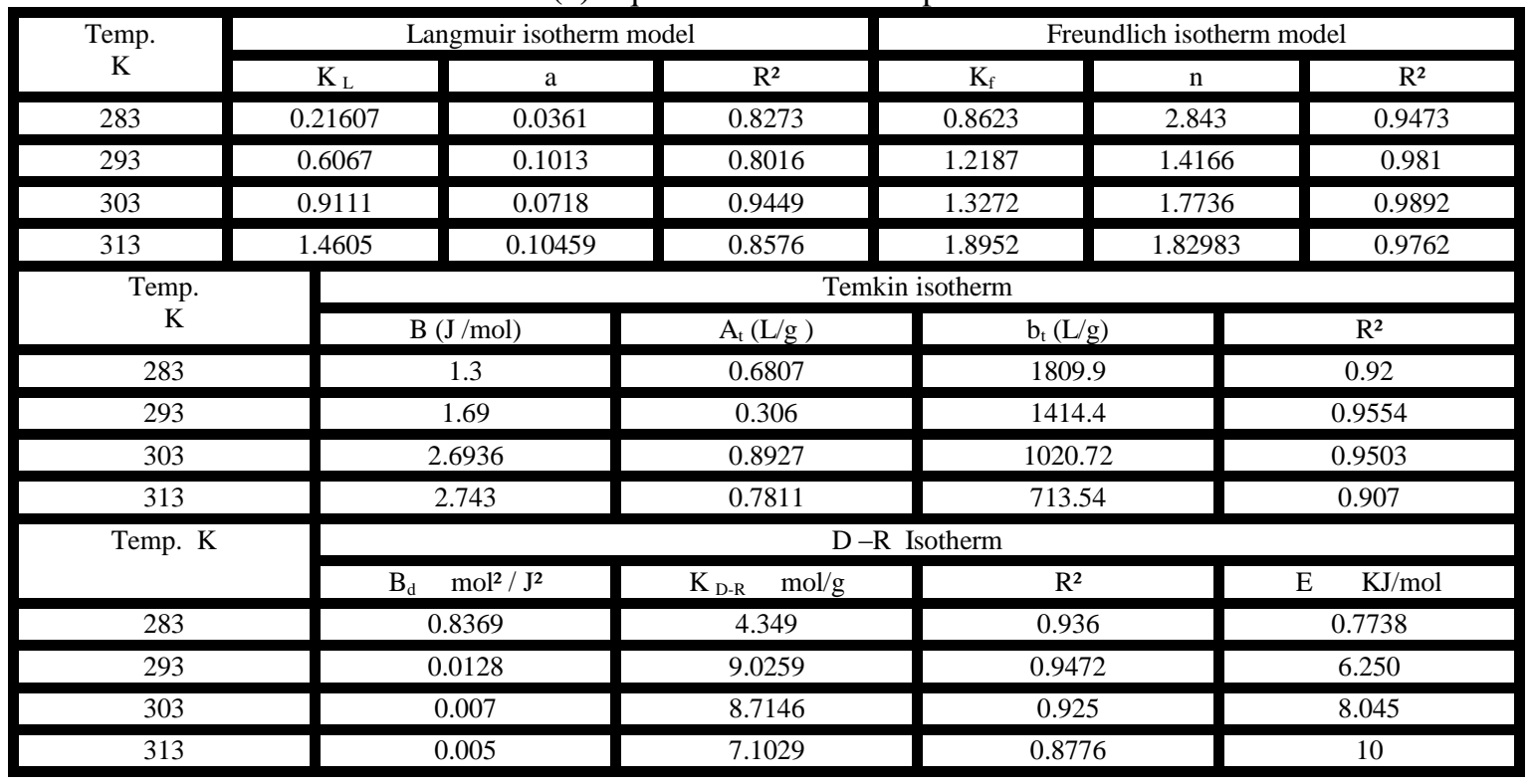

Table (3) Langmuir $\mathrm{R}_{\mathrm{L}}$ Values for adsorption of orange II onto modified CCLW at different temperatures.

\begin{tabular}{|c|c|c|c|c|}
\hline $\begin{array}{c}\mathrm{C}_{\mathrm{O}} \\
\mathrm{mg} \cdot \mathrm{L}^{-1}\end{array}$ & \multicolumn{3}{|c|}{$\mathrm{R}_{\mathrm{L}}$ Value } \\
\hline & $283 \mathrm{~K}$ & $293 \mathrm{~K}$ & $303 \mathrm{~K}$ & 0.079 \\
\hline 10 & 0.3487 & 0.1427 & 0.1127 & 0.0285 \\
\hline 25 & 0.1689 & 0.058 & 0.047 & 0.0148 \\
\hline 50 & 0.0907 & 0.031 & 0.0236 & 0.0094 \\
\hline 75 & 0.0602 & 0.01952 & 0.0152 & \\
\hline
\end{tabular}


Characteristics of azo-dye onto surfactant modified chromium contained leather waste

\begin{tabular}{|l|l|l|l|l|}
\hline 100 & 0.0451 & 0.0147 & 0.0112 & 0.0069 \\
\hline
\end{tabular}

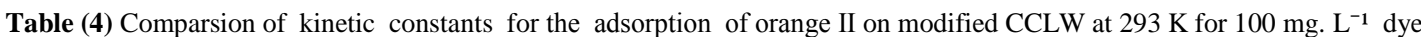

\begin{tabular}{|c|c|c|c|c|c|}
\hline \multicolumn{3}{|c|}{ First - order kinetic model } & \multicolumn{3}{|c|}{ Second - order kinetic model } \\
\hline $\begin{array}{c}\mathrm{q}_{\mathrm{l}} \\
(\mathrm{mg} / \mathrm{g})\end{array}$ & $\begin{array}{c}\mathrm{K}_{1} \\
(\min )^{-1}\end{array}$ & $\mathrm{R}^{2}{ }_{1}$ & $\begin{array}{c}\mathrm{q}_{2} \\
(\mathrm{mg} / \mathrm{g})\end{array}$ & $\begin{array}{c}\mathrm{K}_{2} .10^{-2}(\mathrm{~g} / \mathrm{mg} \\
. \mathrm{min})\end{array}$ & $\mathrm{R}_{2}^{2}$ \\
\hline 7.94 & 0.021 & 0.9501 & 11.2108 & 0.254 & 0.9802 \\
\hline \multicolumn{3}{|c|}{ Elovich model } & \multicolumn{3}{|c|}{ Intrapartical Diffusion } \\
\hline $\begin{array}{c}\mathrm{B} \\
\left(\mathrm{g}-\mathrm{mg}^{-1}\right)\end{array}$ & $\left.{ }_{\left(m g . g^{-1}\right.}^{\alpha} \cdot \min ^{-1}\right)$ & $\overline{\mathrm{R}^{2}}$ & $\begin{array}{c}\mathrm{K}_{\mathrm{ipd}} \\
\left(\mathrm{mg} \cdot \mathrm{g}^{-1} \cdot \min \right)^{-0,5}\end{array}$ & $\begin{array}{c}\mathrm{C} \\
\left(\mathrm{mg} \cdot \mathrm{g}^{-1}\right)\end{array}$ & $\mathrm{R}_{2}^{2}$ \\
\hline 0.4159 & 0.5153 & 0.9115 & 0.6567 & 1.4342 & 0.8931 \\
\hline
\end{tabular}

Table (5) Values of thermodynamic parameters for the adsorption of orange II at various temperature

\begin{tabular}{|c|c|c|c|c|c|c|}
\hline \multirow{2}{*}{$\begin{array}{c}\mathrm{C}_{\mathrm{O}} \\
\mathrm{mg} . \mathrm{L}^{-1}\end{array}$} & \multicolumn{4}{|c|}{$-\Delta \mathrm{G}\left(\mathrm{J} . \mathrm{mol}^{-1}\right)$} & \multirow{2}{*}{$\begin{array}{c}\Delta \mathrm{H}^{0} \\
\mathrm{KJ} \cdot \mathrm{mol}^{-1}\end{array}$} & \multirow{2}{*}{$\begin{array}{c}\Delta \mathrm{S}^{0} \\
\mathrm{~J} \cdot \mathrm{mol}^{-1}\end{array}$} \\
\hline & $283 \mathrm{~K}$ & $393 \mathrm{~K}$ & $303 \mathrm{~K}$ & $313 \mathrm{~K}$ & & \\
\hline 25 & 3490.5 & 5221.6 & 6992.6 & 8738.02 & 45.89 & 174.45 \\
\hline 50 & 2487.9 & 3515.88 & 4543.18 & 5570.78 & 26.59 & 102.76 \\
\hline 75 & 3116.2 & 3577.7 & 4338.03 & 5404.48 & 18.59 & 76.66 \\
\hline 100 & 990.7 & 2080.37 & 3170.1 & 4259.8 & 29.85 & 108.97 \\
\hline 125 & 1807.78 & 2680 & 3567.1 & 442.7 & 22.92 & 87.36 \\
\hline
\end{tabular}

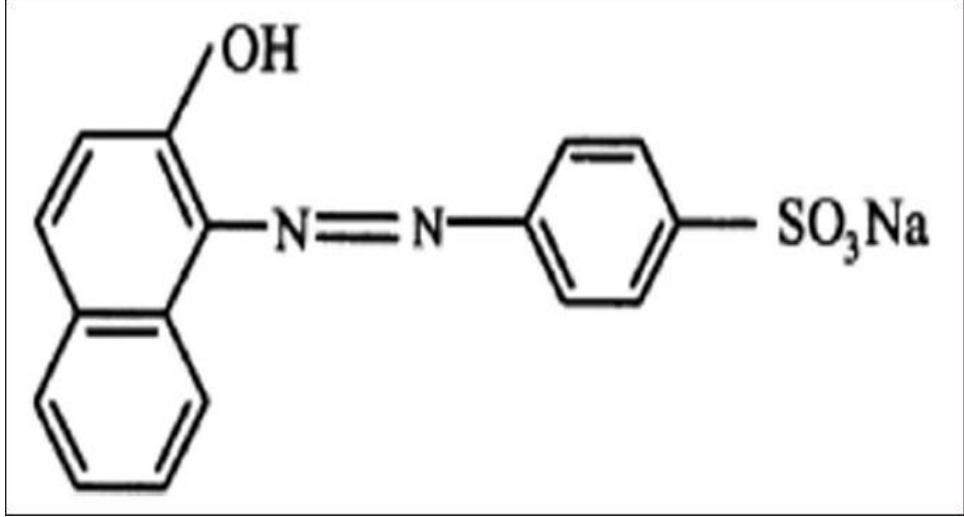

Fig (1) Chemical structure of orange II.

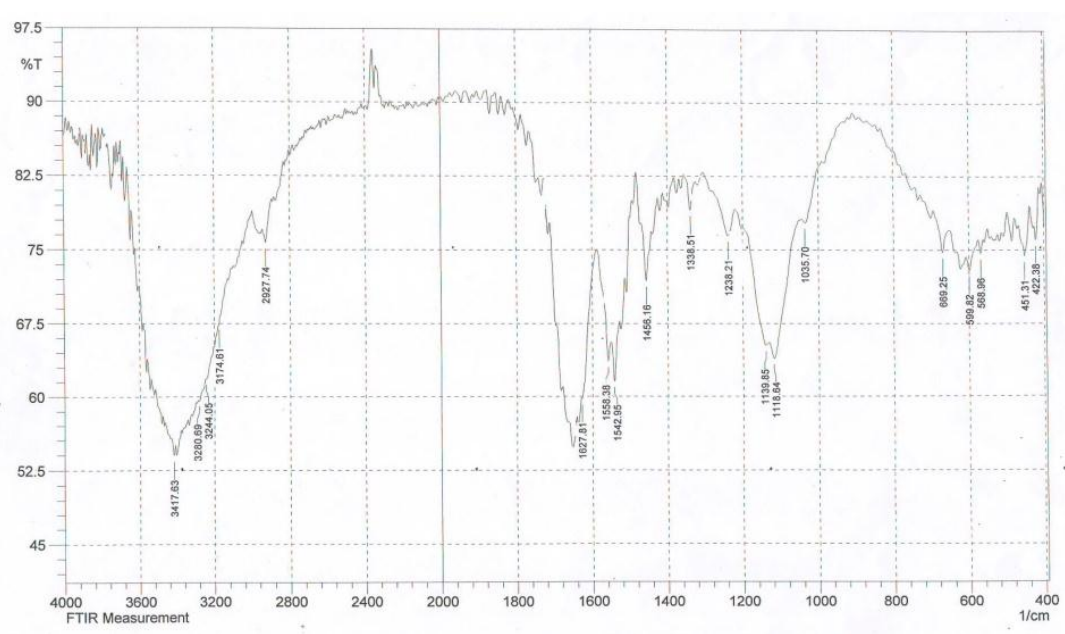

Fig (2) FTIR of MO-CCLW . 


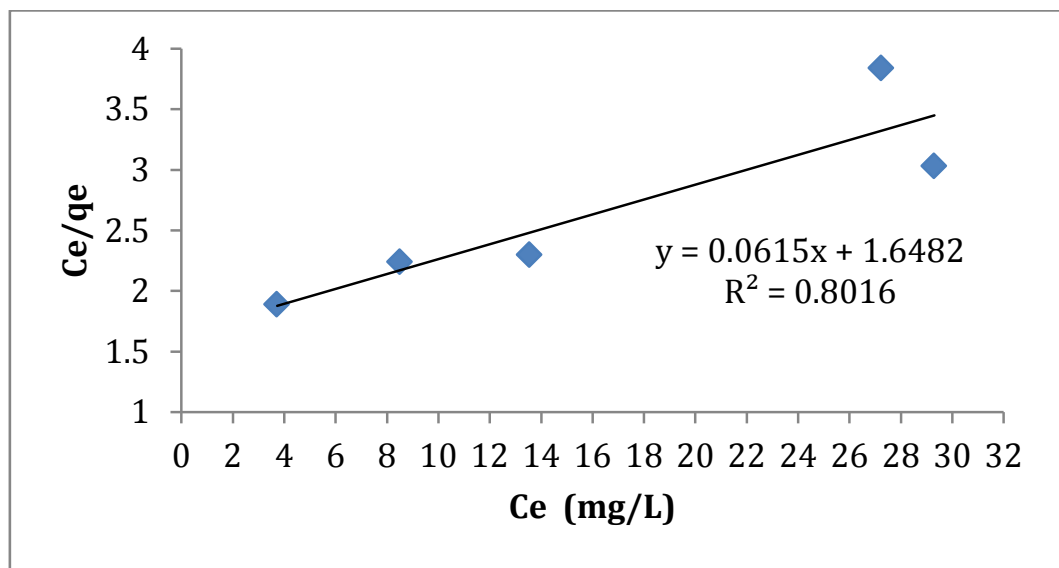

Fig (3) Langmuir isotherm plot for adsorption of orange II onto MO-CCLW at $293 \mathrm{~K}$.

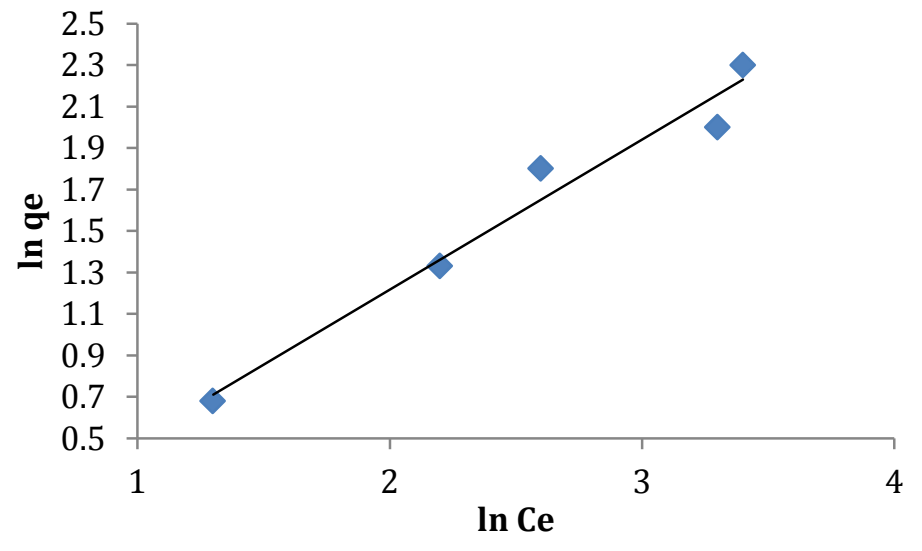

Fig (4) Freundlish isotherm plot for adsorption of orange II onto MO-CCLW at 293K .

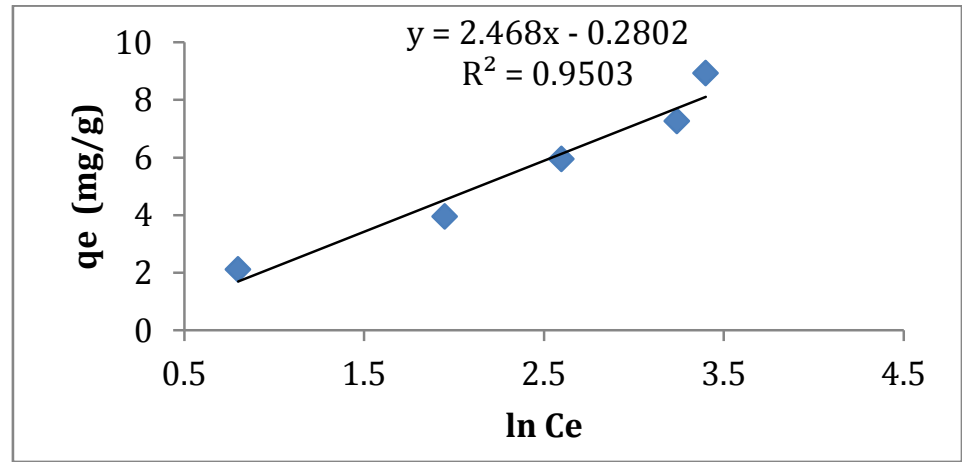

Fig (5) Temkin isotherm plot for adsorption of orange II onto MO -CCLW at 303K .

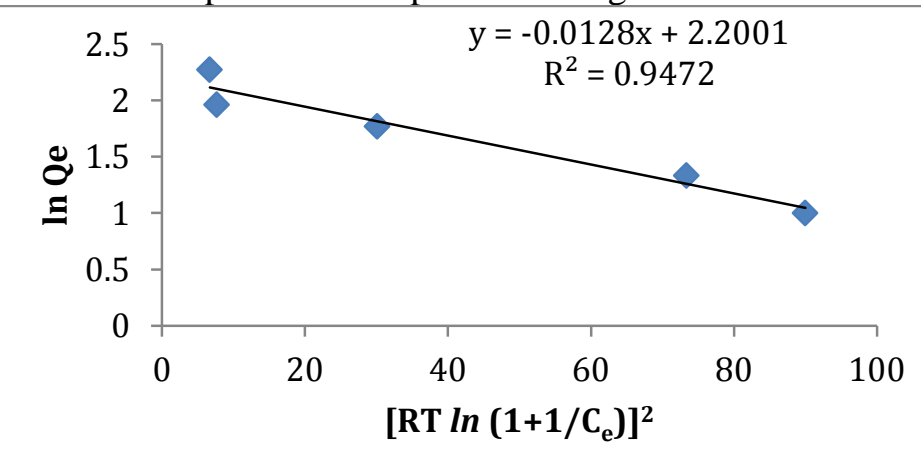

Fig (6) Dubinin -Radushkevich isotherm model for adsorption of orange II onto MO-CCLW at 293K. 


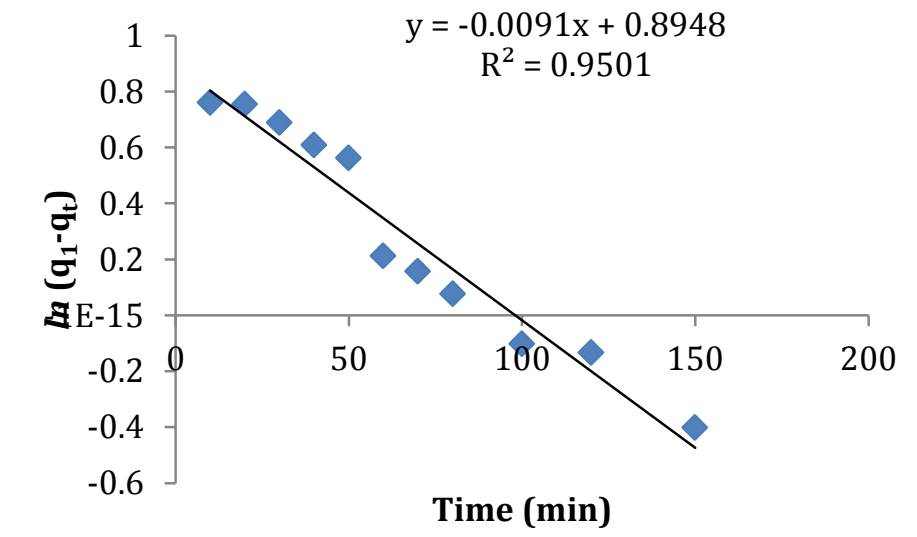

Fig (7) First order plot for adsorption of orange II onto MO-CCLW at $293 \mathrm{~K}$ for $\left(\mathrm{Co}=100 \mathrm{mg} . \mathrm{L}^{-1}\right)$.

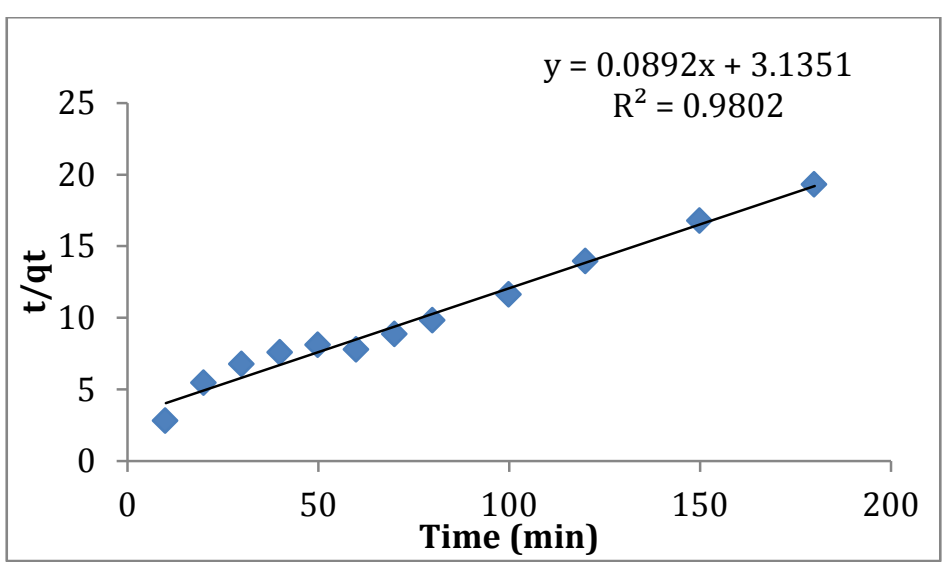

Fig (8) Second order plot for adsorption of orange II onto MO-CCLW at 293K for $\left(\mathrm{Co}=100 \mathrm{mg} . \mathrm{L}^{-1}\right)$

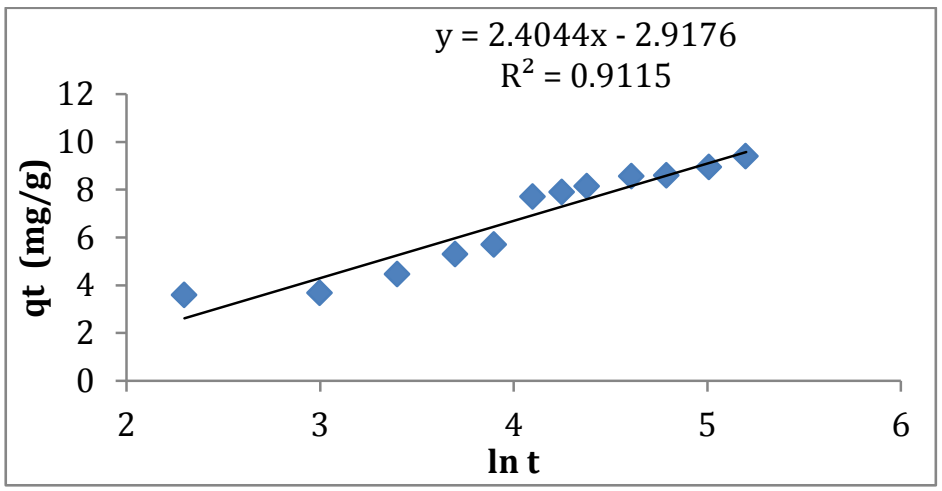

Fig (9) Elovich plot for adsorption of orange II onto MO-CCLW at 293K for ( Co $=100 \mathrm{mg} . \mathrm{L}^{-1}$

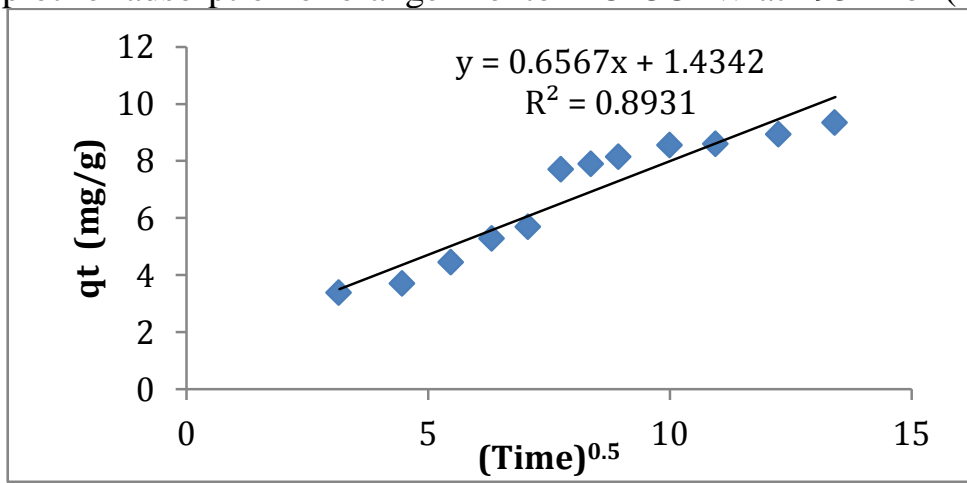

Fig (10) Intra particle plot for adsorption of orange II onto MO-CCLW at $293 \mathrm{~K}$ for $\left(\mathrm{Co}=100 \mathrm{mg} . \mathrm{L}^{-1}\right)$ 


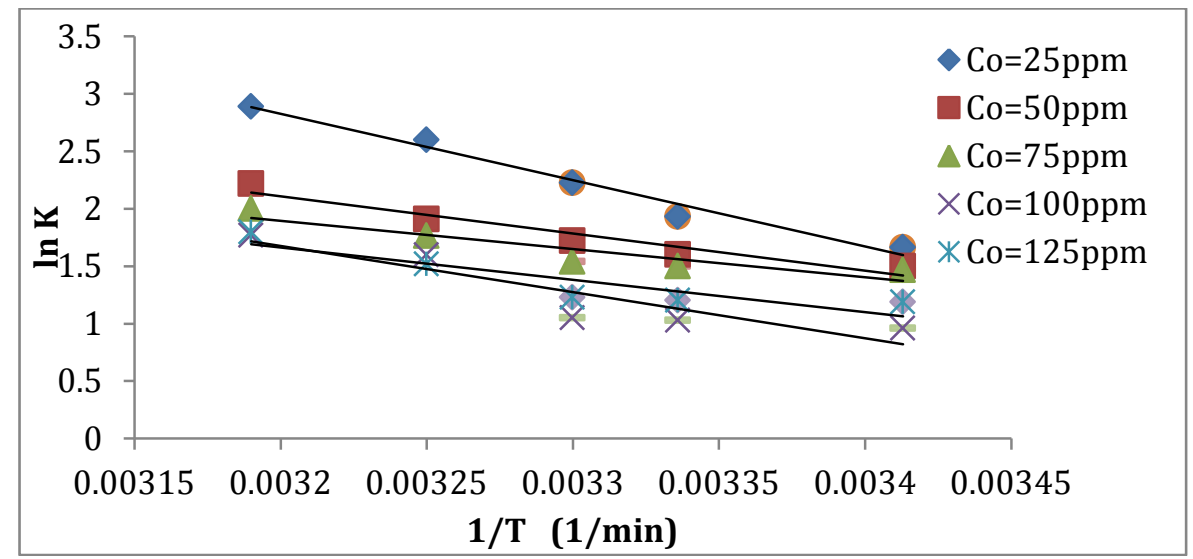

Fig (11) Plot of 1/T Vs . $\ln \mathrm{K}$ for the adsorption of orange II onto MO-CCLW .

\section{Conclusion}

The present work deals with the using modified chromium containing leather waste with cationic surfactant as a low -cost adsorbent to remove anionic dye from aqueous solution. Among various models of adsorption isotherm applied the freundlich model agreed well with experimental data -moreover the results indicate that the adsorption process onto the MO - CCLW follows the pseudo second order rate model with intraparticle diffusion being the rate controlling step. The Thermodynamic study revealed an endothermic and spontaneous process .This study showed the MO-CCLW to be highly efficient adsorbing material .

\section{References}

[1]. R.Wanchanthuek and W. Nunrung, The adsorption study of methylene blue onto Mgo from various preparation methods , Journal of Environmental science and Technology 4 (5), $2011,534-542$.

[2]. O.Gok, A.S.Ozcan .and A .ozcan, Adsorption behavior of atextile dye of reactive Blue 19 from aqueous solutions onto modified bentonite, Appl. Surf . Sci. , 256, 2010, 5439 -5443.

[3]. E.V . Veliev ,T.OZturk , S.Veli , A.G.Fatullayev ,Application of diffusion Model for adsorption of azo reactive dye or pumice , Polish J. , Environ Stud. , 15 (2) ,2006, 347 -353 .

[4]. F.Kargi and S .Ozmihci, Biosorption performance of powered activated sludge for removal of different dye stuffs, Enzyme and Microbial Technology , 35, 2004, $267-271$.

[5]. V. Meshiko, L. Markovska, M . Minchev, A . E . Rodrigues, Adsorption of basic dyes on granular activated carbon and natural Zeolite, Water Research, 35 (14),2001, 3357.

[6]. S. Wang, H . Li , L. X 4 , Application of Zeolite MCM -22 for basic dye removal waste water, J . Colloid interface . Sci. , 295 , $2006,71-78$.

[7]. S.C.R.Santos, R.A.R.Bonaventura , Adsorption modeling of textile dyes by sepiolite , Appl.Clay Sci. , 42 , 2008 , $137-145$.

[8]. B.K .Nandi, A. Goswami and M.K.Purkait, Removal of cationic dyes from aqueous solutions by kaolin , kinetics and equilibrium studies , Applied Clay Sci. , 42, 2009 , 583 - 590.

[9]. M.J .Iqbal and M . N .Ashiq,Adsorption of dyes from aqueous solutions on activated charcoal , J. Hazard .Mater , B , 139 , 2007, 57-66.

[10]. H . Moazed, Ammonium ion removal from wastewater by anatural resin , J. Environ. Sci. Technol. , 1, 2008 , 11-18

[11]. R .S .Souza H.S.Didi , M.G.C.Silva , Removal of benzene from aqueous solution using raw red mud , Chemical Engineering Transaction , 24, 2011, 1225-1230.

[12]. C. Hsin-Mei ,C.Ting -Chien , P. San -De , H .L . Chiang, Adsorption characteristics of orange II and chrysophenine on sludge adsorbent and activated carbon fibers , Journal of Hazardous Materials , 161 , 2009 , 1384-1390 .

[13]. V .K. Gupta, A.Mittal,V. Gajbe, J .Mittal, Removal and recovery of the hazardous azo dye acid orange 7 through adsorption over waste materials : bottom ash and de-oiled soya , Industrial and Engineering Chemistry Research , 45 , 2006 , 1446 -1453.

[14]. J .Ma , J .ZZou, B .Cui ,C .Yao, D .Li, Adsorption of orange II dye from aqueous solutions using phosphoric_acid modified clam shell powder, Desalination and Water Treatment , 51, 2013, 6536-6544.

[15]. X . Jin , M - 9 .Jiang ,X - 9 .Shan, Z - g .Pei , Z .Chen, Adsorption of methylen blue and orange II onto unmodified and surfactant -modified zeolite, Journal of Colloid and Interface Science, 328 (2) ,2008, 243-247.

[16]. O .Santos, C.Castelli , M. Oliveira , A . Neto , M .Silva , Adsorption of synthetic orange Dye wastewater in organoclay, Chemical Enginerring Transactions ,32, 2013, 307-312.

[17]. L.Abramian ,H.EI-Rassy, Adsorption kinetics and thermodynamics of azo-dye orange 11 onto highly porous titania aerogel , Chemical Engineering Journal , 150, 2009, 403-410.

[18]. O . Ceyhan, D . Baybas ,Adsorption of some textile dyes by Hexadecyl trimethyl ammonium Bentonite ,Turk . J .Chem. , 25 , $2001,193-200$.

[19]. N . Zaghbani, A .Hafiane , M. Dhahbi , Removal of safranin T from wastewater using enhanced ultrafiltration , Desalination , 222 , $2008,318-356$.

[20]. S . Sonauwane, P .Chaudhari, S Ghodke, S. Phadtare, S .Meshram, Ultrasound assisted adsorption of basic dye onto organically modified bentonite (nanoclay ), Journal of scientific and Industrial Research , 68 , 2009, 162-167.

[21]. L . Zhu , X .Chen, Sorption of phenol, P-nitrophenol, and aniline to dual cation organobetonites from water , Environmental Science and Technology , 34, 2000, 468-475.

[22]. V.Renugopalakrishnan, G.Chaudarakasan, S.Moore , T.B.Hutson , C.V.Berney , S.B.Ravejeudra , Bound water in collagen ; evidence from Fourier taransform infrared and Fourier transform infrared photoacoustic spectroscopic study , Macromolecules , 22 , 1989 , 4121-4124. 
[23]. I .Langmuir ,Constitution and fundamental properties of solids and liquids , Journal of Hazardous Material, 139, 2007, 57-66 .

[24]. Y .S .HO , C.T. Huang and H .W .Huang, Equilibrium sorption isotherm for metal ions on tree fern ,Process Biochem., 37 , 2002 , 1421-1430.

[25]. M.A.Shouman, W.E.Rashwan, studies on adsorption of basic dyes on activated carbon from phragmites australis ( common reed ) universal , Journal of Environmental Research and Technology , 3 (2), 2012, 119-134.

[26]. A .Tabak, E .Eren, B . Afsin, B. Caglar, Determination of adsorptive properties of aTurkish Isepiolite for removal of Reactive Blue 15 anionic dye from aqueous solutions, J.Hazard . Mater, 161 , 2009, 1087-1094.

[27]. F .A . Dawodu, G .K . AKpomie, I.C. Ogbu, Isotherm modeling on the Equilibrium sorption of cadmium (II) from solution by Agbani clay, International Journal of Multidisciplinary Sciences and Engineering , 3 (9) ,2012 , 9-14 .

[28]. P.Sivakumar,P.N.Palanisamy, Adsorption Studies of basic red 29 by anon conventional activated carbon prepared from euphorbia antiquorum L , Int . J .Chem .Tech .Res ; 1 (3), 2009, 502-510

[29]. R .Rajeshkannan ,M . Rajasimman , N . Rajamoban , Removal of Malachite Green from aqueous solution using Hydrilla Verticillata_Optimization, Equilibrium and Kinetic studies ,International Journal of Civil and Environmental Engineering , 2 (4) 2010, 222-227.

[30]. E .Khosla, S .Kaur, P .N.Dave, Surfactant modified tea Waste as novel adsorbent for basic dye, Der chemical Sinica, 2 (5), 2012 , 87-102.

[31]. Z .AKsu, A .I .Tatll , O .Tunc ,Acomparative adsorption / biosorption study of Acid Blue 161 ; effect of temperature an equilibrium and kinetic parameters , Chemical Engineering Journal , 142 , 2008, 23-29.

[32]. M.Sarkevr , P.K. Acharya , B.Bhattacharya, Modeling the adsorption Kinetics of some priority organic pollutants in water from diffusion and activation energy parameters, Journal of Colloid and Interface Science, 266, 2003, 28-32 .

[33]. W.J. Weber, J.C.Morriss, Kinetics of adsorption on carbon from solution, Journal of the Sanitary Engineering Division , 89 , $1963,31-60$.

[34]. I .Chaari , F.Jamoussi, Application of activated Carbon for Vat dye removal from aqueous Solution, Journal of Applied Sciences in Environmental Sanitation .6 (3) , 2011 , 247-256

[35]. C.K.Jain, Adsorption of Zinc into bed sediments of the River Ganga , Adsorption models and Kinetics, Hydrological Sciences Journal-des-Sciences Hydrogiques , 46 (3) , 2001 , 419-434 . 